\title{
An examination of the relationship between systemic punishment and systemic frustration
}

\author{
SHELDON G. LEVY \\ Wayne State University, Detroit, Michigan 48202
}

\begin{abstract}
Political scientists and sociologists have frequently explained political revolution in terms of individual frustration. The frustration has been inferred from changes in overall indicators of societal conditions. This analytic approach may commit the ecological fallacy since individual responses are inferred from group measures. Data were collected from 445 registered voters in the city of Detroit. The mail survey examined the relationship between individual reports of payoffs in institutional settings, such as educational achievement and income and the individual's perceived frustration. Greater payoffs were associated with less frustration at statistically significant levels. Two conclusions were considered important in terms of the previous research. First, relationships were consistent with the reasoning in previous work, although they did not eliminate the possibility of the ecological fallacy. Second, a large proportion of the variance in individual frustration was not accounted for by the objective measures of payoffs in institutional settings.
\end{abstract}

Political scientists and sociologists have frequently hypothesized a relationship between the individual's frustration (frequently referred to as relative deprivation) and the likelihood of political violence. Davies (1969) has used the concept of frustration to hypothesize that revolutions are preceded by rising expectations that develop as a result of a long period of improvement (usually economic). Revolution is likely to occur when there is a sudden decrease in payoffs. Feierabend, Feierabend, and Nesvold (1969) report data consistent with this interpretation, since greatest political instability was reported for countries in which education, which was used as an index of expectation, was increasing, but income was decreasing. Gurr (1972) has expanded the variables that are predictive of rebellion, while Snyder and Tilly (1972) disagree with Davies' interpretations (see also Davies, 1974; Snyder \& Tilly, 1974).

Although the Davies (1969) research was based on case studies, the other studies were based on macroquantitative cross-national research. However, all have posited psychological processes within individuals that have not directly been investigated. Instead, overall societal measures such as changes in per capita income and literacy levels have been used to infer amounts of frustration in order to account for changes in the amount of political violence.

One problem that may arise is known as the ecological fallacy. Simply stated, the fallacy involves assumptions about the relationship between changes in a summary measure, such as a mean and changes in the individual units. Consequently, for example, increases in per capita income could be associated with increases in income for some individuals and decreases for others. In addition, increases may lead to greater felt satisfaction on the part of some individuals compared to others. McKendry and McKendry (1972) and Seeman (1972) report results that support the notion of differential reactions within various subgroups in the population when overall measures of the society may indicate changes in only one direction.

None of the above studies explicitly examined the amount of frustration as a function of punishment in great detail, although the McKendry and McKendry (1972) data indicate that perceptions may actually be greater for those who are obtaining smaller actual economic payoffs. This fact, in conjunction with the inconsistent results that have been found across studies, indicates that the relationship between systemic punishment and systemic frustration should be examined directly with the individual as the unit of analysis. A positive relationship between the two variables when individuals are the unit is a necessary but not a sufficient prerequisite to the hypothesis that societal conditions can be used to infer subjective reactions.

Systemic punishment or reward was defined as the objective payoffs of an individual within institutional settings (e.g., income, education, level of housing, etc.). Systemic frustration was defined as the amount of goal blockage perceived by the individual in an institutional setting. The two measures are, therefore, independently defined. An individual may have a high level of education relative to another (i.e., less systemic 
punishment) but may perceive greater goal blockage in terms of desired education (i.e., greater systemic frustration).

\section{METHOD}

\section{Sample}

Data were collected based on a mail sample of 1,125 respondents who were randomly selected from the voter registration lists of 20 randomly selected precincts in the city of Detroit. Interview schedules were sent during the spring of 1973, and resulted in a return of 445 completed instruments (a $40 \%$ response rate).

\section{Operationalization}

Race, income, and education were used as indices of systemic punishment. The individual was also asked to assess how satisfactory his neighborhood was in terms of crowdedness, personal safety, and local problems with drugs and drinking. The punishment variable was further extended through a series of questions that asked whether the respondent had experienced discrimination in the past in jobs, housing, and education. Since this measure involves a respondent's perception (as do the neighborhood questions), it may be a mixture of both objective conditions and frustration. Systemic frustration was specifically measured by asking respondents how difficult they felt it would be for them to obtain help, if they needed it, within particular institutional settings (e.g., obtaining a loan, obtaining medical help, obtaining legal help). They were also asked how satisfied they were with their educations, with their opportunities to advance on the job, and with changes in their financial situations.

It is apparent that in a survey, assessment of these variables is dependent upon self-report. However, census data are also obtained in this manner, and this information is frequently used in cross-national macrostudies. It therefore seems reasonable to accept the respondent's report of race, education, income, sex, age, and so on, as reasonably accurate statements about the objective situation. Of course, statements of past discrimination may involve perception and substantial distortion of the objective environment. Finally, assessment of future consequences must be classified as subjectively defined.

\section{RESULTS}

Composite indices of past discrimination, systemic frustration, and physical conditions in the neighborhood were formed based upon high correlations of the separate items. Table 1 presents the correlations among the variables. These correlations indicate that race is closely related to the discrimination, frustration, and neighborhood variables, with blacks reporting more discrimination, more frustration, and worse neighborhood conditions. Income is primarily related to frustration, and neighborhood and education are related to systemic frustration. Since race, income, and education are punishment variables, the results indicate a relationship between punishment and frustration. However, they also indicate that frustration includes variation not accounted for by these particular punishment indices. Therefore, the data indicate that direct inferences of psychological reactions from societal conditions must be made cautiously, especially if one is assuming that it is the frustration level that is the determinant of the overt response. This point is reinforced by a multiple regression of race, education, income, age, and regularity of church attendance to a variable that was formed by combining the frustration and discrimination variables. The multiple $\mathrm{R}$ was .57 $[F(5,339)=33.4, p<.001]$, indicating that $67 \%$ of the variation in the frustration variable was not accounted for by the cumulative effect of these variables. (Race was the dominant predictor, with income also contributing substantially to the multiple R. Age contributed slightly, while neither education nor regularity of church attendance provided significant independent components to R.)

\section{CONCLUSIONS}

This study of the relationship between systemic punishment and systemic frustration indicated that while the two are positively related, a large proportion of variance in the frustration variable is not accounted for by the variations in the punishment variables when the individual is the unit of analysis. The error in inferring the frustration occurring in individuals from macromeasures of systemic punishment is clear, although these results do not contradict the position taken in the political science research since they indicate changes in frustration that are consistent with changes in the demographic measures.

Of course, it is still possible for the ecological fallacy to

Table 1

Correlations Among Systemic Punishment and Systemic Frustration Variables

\begin{tabular}{|c|c|c|c|c|c|}
\hline Variable & Race & Income & Education & $\begin{array}{c}\text { Past Dis- } \\
\text { crimination }\end{array}$ & $\begin{array}{l}\text { Systemic } \\
\text { Frustration }\end{array}$ \\
\hline $\begin{array}{l}\text { Race } \\
\text { Income } \\
\text { Education } \\
\text { Past Discrimination } \dagger \\
\text { Systemic Frustration } \dagger \dagger \\
\text { Physical Conditions in Neighborhood }\end{array}$ & $\begin{array}{l}-.15^{* *} \\
-.13^{*} \\
.44 * * * \\
.40 * * * \\
.26 * * *\end{array}$ & $\begin{array}{l}.41 * * * \\
-.11 * \\
-.38 * * * \\
-.20 * * *\end{array}$ & $\begin{array}{l}-.02 \\
-.23 * * * \\
-.07\end{array}$ & $\begin{array}{l}.46 * * * \\
.43 * * *\end{array}$ & $.40 * * *$ \\
\hline $\begin{array}{l}\text { Two-tailed probabilities: } \\
\quad \text { tDiscrimination in jobs, place to live, } \\
\text { t†Evaluation of ability to obtain financ } \\
\text { opportunity to advance, improvement in } \\
\text { t+ Satisfaction with neighborhood, cro } \\
\text { index). }\end{array}$ & $\begin{array}{l}{ }^{*} p<.05 \\
\text { tional syst } \\
\text { rom a ban } \\
\text { ancial situ } \\
\text {, safety, }\end{array}$ & $\begin{array}{l}\text { osite in } \\
\text { ate med } \\
\text { satisfac } \\
\text { ems wit }\end{array}$ & $\begin{array}{l}{ }^{*} p<.01 \\
\text { legal help if } n \\
\text { vith present fi } \\
\text { s and drinkin }\end{array}$ & satisfacti & $\begin{array}{l}* * * p<.001 \\
\text { th education, } \\
\text { posite index) } \\
d \text { (composite }\end{array}$ \\
\hline
\end{tabular}


occur, since even these findings do not indicate that summary measures of the group predict to particular subgroups or individuals in the population. This research does indicate that even when the individual is measured on both variables, predictions from the demographic data to the subjective reactions have limitations.

\section{REFERENCES}

DAvis, J. C. The J-curve of rising and declining satisfactions as a cause of some great revolutions and a contained rebellion. In H. D. Graham \& T. R. Gurr (Eds.), The history of violence in America. New York: Praeger, 1969.

DAvies, J. C. The J-curve and power struggle theories of collective violence. American Sociological Review, 1974, 39, 607-610.

Feierabend, I. K., Feierabend, R. L., \& Nesvold, B. A. Social change and political violence: Cross-national patterns. In H. D.
Graham \& T. R. Gurr (Eds.), The history of violence in America. New York: Praeger, 1969.

GURR, T. R. Sources of rebellion in Western societies: Some quantitative evidence. In J. F. Short, Jr. \& M. E. Wolfgang (Eds.), Collective violence. Chicago: Aldine, 1972.

McKendRY, J. M., \& McKendry, M. S. Differences in actual and perceived progress during early stages of economic development. Journal of Applied Social Psychology, 1972, 2, 77-93.

Seeman, M. The signals of '68: Alienation in pre-crisis France. American Sociological Review, 1972, 37, 385-402.

SNYDER, D., \& TILLY, C. Hardship and collective violence in France, 1830-1960. American Sociological Review, 1972, 37, 520-532.

SNYDER, D., \& TILLY, C. On debating and falsifying theories of collective violence. American Sociological Review, 1974, 39, 610-613.

(Received for publication January $31,1979$. ) 